\title{
Parâmetros genéticos de uma população de milho em níveis contrastantes de nitrogênio ${ }^{1}$
}

\author{
Genetic parameters of a maize population in contrasting nitrogen levels
}

\author{
Marcelo Oliveira Soares ${ }^{2 *}$, Glauco Vieira Miranda ${ }^{3}$, Lauro José Moreira Guimarães ${ }^{4}$, Ivanildo Evódio Marriel $^{4}$ \\ e Claudia Teixeira Guimarães ${ }^{4}$
}

\begin{abstract}
Resumo - O objetivo desse trabalho foi caracterizar uma população de milho por meio da análise de parâmetros genéticos em baixa e alta disponibilidade de nitrogênio. Assim, foi realizado experimento em delineamento em blocos ao acaso, com 162 linhagens, em dois ambientes contrastantes quanto à disponibilidade de nitrogênio, em esquema fatorial com três repetições. A população apresentou variabilidade genética para produtividade de grãos em baixo nitrogênio, com redução na média de altura de espiga, teor de clorofila, número de espigas, peso de espiga e produtividade de grãos em relação ao ambientes sem estresse. Os coeficientes de correlação genética entre produtividade de grãos e as outras características variaram de acordo com as doses de nitrogênio aplicadas. O número de espigas apresentou alta correlação genética com produtividade de grãos sob estresse, além de maior herdabilidade comparada à obtida em alto nitrogênio, possibilitando assim seu uso na seleção indireta de linhagens produtivas de milho cultivadas sob estresse de nitrogênio.
\end{abstract}

Palavras-chave - Nitrogênio. Milho (Zea mays L.). Estresse abiótico. Herdabilidade.

\begin{abstract}
The aim of this study was to characterize a maize population through the genetic parameters in high and low nitrogen availability. Thus, the experiment was conducted in a randomized block design with 162 lines in two contrasting environments in nitrogen availability in a factorial design with three replications. The population showed genetic variability for grain yield in low nitrogen, reducing the ear height, chlorophyll content, the number of ears, ear weight and grain yield in relation to the environment without stress. The coefficient's genetic correlation between grain yield and other characteristics vary according to levels of nitrogen applied. The number of ears showed high genetic correlation with grain yield under stress and high heritability compared with obtained under a high nitrogen, thus enabling its use for indirect selection of yield lines of maize grown under nitrogen stress.
\end{abstract}

Key words - Nitrogen. Corn (Zea mays L.). Abiotic stress. Heritability.

\footnotetext{
* Autor para correspondência

${ }^{1}$ Recebido para publicação em 12/01/2010; aprovado em 31/01/2011

Pesquisa referente à Dissertação de Mestrado em genética e melhoramento do primeiro autor

${ }^{2}$ Programa de Pós-Graduação em Genética e Melhoramento, Departamento de Fitotecnia, Universidade Federal de Viçosa, Viçosa-MG, Brasil, marcelosoares2001@gmail.com

${ }^{3}$ Departamento de Fitotecnia, Universidade Federal de Viçosa, Viçosa-MG, Brasil, glaucovmiranda@ufv.br

${ }^{4}$ Embrapa Milho e Sorgo, Sete Lagoas-MG, Brasil, lauro@cnpms.embrapa.br, claudia@cnpms.embrapa.br, imarriel@cnpms.embrapa.br
} 


\section{Introdução}

A cultura do milho apresenta demanda elevada por fertilizantes nitrogenados, fazendo com que a aplicação desse nutriente seja extremamente necessária para obtenção de altas produtividades (BASTOS et al., 2008; FIDELIS et al., 2007). Devido aos altos preços dos fertilizantes nitrogenados e ao baixo poder de compra dos agricultores nos países em desenvolvimento, grande parte das lavouras de milho é conduzida sobre condições de deficiência de nitrogênio (BÄNZIGER et al., 1997a). Assim, são justificados os esforços em estudos que visam ao desenvolvimento de cultivares de milho com maior capacidade de aproveitamento do nitrogênio aplicado via fertilização e, também, para desenvolvimento de cultivares que apresentem alta eficiência de absorção e utilização deste nutriente quando cultivados em baixa disponibilidade de nitrogênio no solo.

A obtenção de cultivares de milho mais eficientes no uso de $\mathrm{N}$ pode ser realizada via seleção de genótipos superiores, uma vez que há variabilidade genética para Eficiência de Uso de Nitrogênio (EUN) em milho (GAMA et al., 2002; SILVA et al., 2008; SOARES et al,. 2009; SOUZA et al., 2008; SOUZA et al., 2009). Entretanto, Lafitte et al. (2003) comentam que o progresso na seleção para EUN se torna dificultado devido ao efeito da interação genótipo $\mathrm{x}$ ambiente, além do baixo coeficiente de herdabilidade obtido para produção de grãos sobre condição de estresse devido à natureza quantitativa dessa variável e o pronunciado efeito ambiental. Uma alternativa que pode ser empregada nesta situação é a utilização de características secundárias para auxiliar no processo seletivo, procedendo-se seleção indireta ou a composição de índices (MIRANDA et al., 2005). Segundo Edmeades et al. (1998), uma característica secundária ideal deve ser associada geneticamente à produtividade de grãos sob estresse, apresentar-se altamente herdável, com alta variabilidade genética, mostrar-se de fácil e rápida mensuração, sendo estável durante vários períodos de medição, e observável durante ou antes do florescimento para que genitores indesejados não sejam cruzados. Algumas características como o número de espigas por planta, senescência foliar e o intervalo entre o florescimento masculino e feminino foram propostas para auxiliar no processo seletivo sobre condições de baixo $\mathrm{N}$ no solo (BÄNZINGER; LAFFITE 1997b). Sendo estas últimas mais indicadas para esses estudos por se tratar de caracteres que se manifestam antes da fertilização, fato que evita cruzamentos estocásticos.

Neste contexto, o objetivo desse trabalho foi estimar parâmetros genéticos em uma população de linhagens endogâmicas recombinantes de milho tropical, conduzida sob níveis contrastantes de nitrogênio no solo.

\section{Material e métodos}

Foi utilizada uma população de milho constituída por 160 linhagens endogâmicas recombinantes, em S6, originadas do cruzamento entre duas linhagens tropicais, CMS28-7.1 e CMS28-10.2. Estas linhagens parentais, utilizadas como testemunhas experimentais, foram classificadas como contrastantes no uso de nitrogênio, de acordo com a produção de grãos em ambientes com baixa disponibilidade deste nutriente (PURCINO et al., 2008).

O experimento foi realizado no campo experimental da Embrapa Milho e Sorgo em Sete Lagoas, MG. De acordo com a análise do solo não foi necessária a aplicação de calcário para correção da acidez. Em relação à adubação de plantio, foram aplicados $90 \mathrm{~kg} \mathrm{ha}^{-1}$ de $\mathrm{P}_{2} \mathrm{O}_{5}$ e $48 \mathrm{~kg} \mathrm{ha}^{-1}$ de $\mathrm{K}_{2} \mathrm{O}$ para o suprimento de fósforo e potássio, respectivamente. A adubação nitrogenada foi realizada utilizando duas doses de nitrogênio (Alta e Baixa). No baixo N (N-), foram aplicados $12 \mathrm{~kg} \mathrm{ha}^{-1}$ de nitrogênio no plantio e no alto $\mathrm{N}(\mathrm{N}+), 120 \mathrm{~kg} \mathrm{ha}^{-1}$ de nitrogênio, parcelados em $12 \mathrm{~kg} \mathrm{ha}^{-1}$ no plantio e $108 \mathrm{~kg} \mathrm{ha}^{-1}$ em cobertura. A adubação de cobertura foi dividida em duas aplicações realizadas nos estádios de 4 e 8 folhas completamente desenvolvidas, utilizando uréia como fonte de nitrogênio. Os tratos culturais foram realizados quando necessários de acordo com as recomendações técnicas para a cultura do milho.

Foi utilizado o delineamento em blocos casualizados com três repetições, em esquema fatorial. O ensaio foi constituído por 162 linhagens (160 linhagens e 2 testemunhas), em duas doses de nitrogênio. A parcela experimental foi constituída por uma linha de $5 \mathrm{~m}$ de comprimento, com espaçamento de $0,8 \mathrm{~m}$ entre linhas e 0,2 entre plantas, com estande final esperado de 62.500 plantas $\mathrm{ha}^{-1}$.

As características avaliadas foram altura de planta (Ap, em cm, após o florescimento masculino, do nível do solo à inserção da folha bandeira, em plantas competitivas na parcela), altura de espiga (Ae, em cm, após o florescimento masculino, do nível do solo até a inserção da espiga superior no colmo em plantas competitivas na parcela), florescimento masculino (Fm, número de dias do plantio até que $50 \%$ das plantas da parcela tivessem iniciado a liberação do pólen), florescimento feminino ( $\mathrm{Ff}$, número de dias do plantio até que $50 \%$ das plantas da parcela tivessem emitido estilo-estigma), número de espiga ( $\mathrm{Ne}$, contadas todas as espigas existentes na parcela, após a colheita), peso de espiga ( $\mathrm{Pe}$, medido o peso de todas as espigas obtidas nas parcelas, em $\mathrm{kg} \mathrm{ha}^{-1}$ ), produtividade de grãos (Pg, pesagem dos grãos debulhados de todas as plantas obtidas na parcela, corrigido para $\mathrm{kg} \mathrm{ha}^{-1}$ e $13 \%$ 
de umidade), peso de 100 grãos (P100, peso médio de oito amostras de 100 grãos das parcelas, em gramas) e o teor de Clorofila (Spad) que foi obtida pela média de seis leituras por parcela, realizadas com o medidor portátil de clorofila SPAD-502, no estádio vegetativo da décima folha. As leituras foram feitas em pontos situados na metade ou a dois terços do comprimento da folha amostrada, a partir da base e a $2 \mathrm{~cm}$ de uma das margens da folha.

Foram realizadas análises de variâncias individuais e verificada a homogeneidade das variâncias residuais para processamento da análise conjunta. Baseado nas esperanças matemáticas do modelo, considerando genótipos $(\mathrm{G})$ e a interação genótipos $\mathrm{x}$ doses de nitrogênio como efeitos aleatórios e doses de nitrogênio $(\mathrm{N})$ como efeitos fixos, foram obtidas as estimativas dos componentes de variâncias e das herdabilidades para as características descritas acima. As médias foram agrupadas segundo o método de Scott e Knott a 5\% de probabilidade, utilizando o software de análises genéticas GENES (CRUZ, 2004).

\section{Resultados e discussão}

De acordo com os resultados das análises de variâncias conjuntas (TAB. 1), observa-se que houve diferença significativa entre as linhagens a $1 \%$ de probabilidade, para todas as características, demonstrando a existência de variabilidade genética na população. A classificação relativa das linhagens para as características altura de planta (Ap), altura de espiga (Ae), teor de clorofila (Spad), florescimento masculino (Fm), florescimento feminino (Ff), número de espigas $(\mathrm{Ne})$, peso de espigas $(\mathrm{Pe})$, produtividade de grãos $(\mathrm{Pg})$ e peso de 100 sementes (P100) foram semelhantes em baixo e em alto nitrogênio, demonstrado pela não significância da interação linhagens $\mathrm{x}$ doses de nitrogênio (TAB. 1). Interação não significativa entre genótipos de milho e doses de nitrogênio para produção de grãos também foi encontrado por Szelés (2007).

A interação é um aspecto importante a ser considerado em um programa de melhoramento, uma vez que essa não somente interfere na recomendação de cultivares como dificulta o trabalho do melhorista na identificação de genótipos superiores em diferentes ambientes (RAMALHO et al., 1993). Paradoxalmente, se não houvesse interação $\mathrm{GxE}$, uma cultivar adaptarse-ia à maioria dos ambientes de cultivo (locais, anos e estações), de forma que um único experimento, conduzido num só local (ainda com repetições), seria suficiente para fornecer resultados universais. Contudo, na realidade, cultivares de ampla adaptação normalmente apresentam produtividades subótimas, o que desperta para a possibilidade de explorar vantajosamente os efeitos dessa interação. Assim, embora os melhoristas tendam a desenvolver uma atitude negativa contra a interação GxE (barreira às elevadas herdabilidades e ganhos com a seleção), deve ser lembrado que interações positivas, associadas com características previsíveis do ambiente, oferecem a oportunidade das produtividades mais elevadas. Logo, interação não é apenas um problema, mas também uma oportunidade a ser aproveitada (DUARTE; VENCOVSKY, 1999).

As diferenças significativas encontradas entre as doses de nitrogênio demonstraram que as quantidades

Tabela 1 - Resumo das análises de Variâncias Conjuntas, para Altura de Plantas (Ap), Altura de Espiga (Ae), Teor de Clorofila (Spad), Florescimento Masculino (Fm), Florescimento Feminino (Ff), Número de Espigas (Ne), Peso de Espigas (Pe), Produção de Grãos (Pg) e Peso de 100 Sementes(P100) avaliados na população de RIL e duas testemunhas, sob Baixa e Alta disponibilidade de nitrogênio no solo

\begin{tabular}{lccrrrrrrr}
\hline $\begin{array}{l}\text { Fontes de } \\
\text { Variação }\end{array}$ & \multicolumn{10}{c}{ Quadrados Médios } \\
\hline & $\mathrm{Ap}$ & $\mathrm{Ae}$ & $\mathrm{Spad}$ & $\mathrm{Fm}$ & $\mathrm{Ff}$ & $\mathrm{Ne}$ & $\mathrm{Pe}$ & $\mathrm{Pg}$ & $\mathrm{P} 100$ \\
\hline RIL & $849,0^{* *}$ & $319,8^{* *}$ & $63,9^{* *}$ & $26,8^{* *}$ & $3,8^{* *}$ & $63,9^{* *}$ & $2837249,6^{* *}$ & $1888265,1^{* *}$ & $56,9^{* *}$ \\
Test & $3168,7^{* *}$ & $918,7^{* *}$ & $108,6^{* *}$ & $5,3^{\text {ns }}$ & $10,0^{\text {ns }}$ & $90,7^{* *}$ & $22591352,0^{* *}$ & $12114632,4^{* *}$ & $44,3^{* *}$ \\
RIL vs Test & $100,9^{\text {ns }}$ & $2,1^{\text {ns }}$ & $132,6^{* *}$ & $17,2^{\text {ns }}$ & $77,3^{*}$ & $88,2^{* *}$ & $3577923,4^{* *}$ & $2477642,6^{* *}$ & $22,5^{\text {ns }}$ \\
Doses & $8326,3^{\text {ns }}$ & $9802,4^{*}$ & $20930,8^{* *}$ & $167,9^{\text {ns }}$ & $170,4^{\text {ns }}$ & $6000,2^{* *}$ & $178533673,4^{* *}$ & $103279865,4^{* *}$ & $14,3^{\text {ns }}$ \\
RIL x Doses & $244,9^{\text {ns }}$ & $38,8^{\text {ns }}$ & $17,9^{\text {ns }}$ & $6,7^{\text {ns }}$ & $7,3^{\text {ns }}$ & $14,5^{\text {ns }}$ & $272468,7^{\text {ns }}$ & $211769,5^{\text {ns }}$ & $14,4^{\text {ns }}$ \\
Tes x Doses & $0,5^{\text {ns }}$ & $13,0^{\text {ns }}$ & $9,2^{\text {ns }}$ & $0,3^{\text {ns }}$ & $14,0^{\text {ns }}$ & $44,0^{\text {ns }}$ & $76002,0^{\text {ns }}$ & $480776,3^{\text {ns }}$ & $15,1^{\text {ns }}$ \\
\hline Resíduo & 211,2 & 52,6 & 15,2 & 5,4 & 7,9 & 17,2 & 318563,2 & 219658,4 & 13,9 \\
\hline
\end{tabular}

*,**, ns: Significativo a 5 e $1 \%$ de probabilidade e não significativos pelo teste $\mathrm{F}$ 
de $\mathrm{N}$ aplicadas (12 e $120 \mathrm{~kg} \mathrm{ha}^{-1}$ ) foram adequadas para diferenciar os ambientes para as características altura de espiga, teor de clorofila, número de espigas, peso de espigas e produtividade de grãos, como apresentado na Tabela 1.

$\mathrm{O}$ estresse de nitrogênio, apesar de ter alterado o comportamento das linhagens em relação a características fisiológicas, como o teor de clorofila, observado pela diferença significativa entre os dois ambientes, não proporcionou alterações nas características de florescimento masculino, florescimento feminino e o peso de 100 sementes (TAB. 1).

$\mathrm{Na}$ avaliação de progênies em campo é comum observarem-se variações que não sejam de origem genética, sendo estas causadas por fatores ambientais ou inerentes ao ensaio, sendo assim incluídas no erro experimental. Esse erro pode ser causado por fatores como a heterogeneidade do material genético, número de repetições, tamanho e forma das parcelas, estande final de plantas, além da heterogeneidade do solo e dos tratos culturais. Segundo Gomes (1990), uma das maneiras de avaliar esse erro é através do uso do coeficiente de variação experimental (CV\%).

Os valores dos coeficientes de variação foram diferentes quando comparamos baixo e alto nitrogênio, tendo sido o erro experimental em baixo $\mathrm{N}$ maior do que em alto N para Ap, Ae, Spad, Ne, Pe, Pg e P100 (TAB. 2), demonstrando menor precisão experimental para estas características na avaliação com baixo nitrogênio no solo. Esse fato ocorreu devido à média entrar como denominador na equação que estima o coeficiente de variação experimental e, sob estresse, as médias destas características tendem a diminuir, refletindo aumentos nas estimativas dos coeficientes de variação. No que concerne à contribuição dos diferentes ambientes para a interação, sua variância é atribuída a uma porção previsível (fixa) que faz parte da variação e que pode ser medida em magnitude e em direção, seu caráter sistemático facilita razoável controle, já sua porção imprevisível (aleatória) faz parte da variação experimental não controlada, por ter natureza indeterminada, isto é, de sentido e direção incertos.

A produtividade de grãos apresentou valores elevados de coeficiente de variação tanto em baixo quanto em alto nitrogênio, sendo de 32,33 e 20,00\% respectivamente. Em estudos de melhoramento de plantas para estresse de baixo nitrogênio é normal a obtenção de CV's mais elevados do que para ambientes sem estresse, pois sob estresse as médias geralmente são menores e os quadrados médios dos resíduos são maiores. A obtenção de maiores coeficientes de variação em ambientes sob estresse foi relatado por Banziger et al. (1997a). Santos et al. (1998) obtiveram coeficientes de variação de 22,3 e 23,4\% para o peso de espiga e produtividade de grãos, respectivamente, avaliando uma população de sintéticos de milho em baixo nitrogênio.

Tabela 2 - Médias, Coeficientes de herdabilidade $\left(\mathrm{h}^{2}\right)$ e coeficientes de variação (CV\%) obtidos a partir da avaliação da população de RILs e duas testemunhas, cultivadas em ambientes contrastantes quanto à disponibilidade de N, para Altura de planta (Ap), Altura de Espiga(Ae), Teor de Clorofila(Spad), Florescimento Masculino(Fm), Florescimento Feminino(Ff), Número de Espigas(Ne), Peso de Espigas(Pe), Produção de Grãos em kg ha-1 $(\mathrm{Pg})$ e Peso de 100 Sementes(P100)

\begin{tabular}{clccccccccc}
\hline \multirow{2}{*}{$\begin{array}{c}\text { Dose de } \\
\text { Nitrogênio }\end{array}$} & Genótipo & \multicolumn{1}{c}{ Características } \\
\cline { 3 - 10 } & RIL & 114,8 & 57,3 & 34,13 & 70,5 & 70,7 & 15,3 & 1615,1 & 1225,26 & 21,95 \\
& CMS28-7.1 & 127,9 & 65,83 & 41,77 & 68,7 & 69 & 17,67 & 3532,5 & 2766,36 & 27,83 \\
& CMS28-10.2 & 95 & 46,25 & 37,5 & 69,7 & 68,7 & 8,33 & 629,17 & 356,5 & 18,64 \\
\multirow{2}{*}{$\mathrm{N}^{-}$} & Média Geral & $112,5 \mathrm{~A}$ & $56,4 \mathrm{~B}$ & $37,8 \mathrm{~B}$ & $69,6 \mathrm{~A}$ & $69,4 \mathrm{~A}$ & $13,7 \mathrm{~B}$ & $1925,5 \mathrm{~B}$ & $1449,3 \mathrm{~B}$ & $22,8 \mathrm{~A}$ \\
& CV(\%) & 15,6 & 12,7 & 13,0 & 3,2 & 3,9 & 30,0 & 29,3 & 32,3 & 16,3 \\
& $\mathrm{~h}^{2}$ & 0,56 & 0,75 & 0,59 & 0,58 & 0,62 & 0,60 & 0,80 & 0,78 & 0,65 \\
\hline & RIL & 120,6 & 63,6 & 43,47 & 69,6 & 69,9 & 20,3 & 2470,18 & 1874,21 & 22,24 \\
& CMS28-7.1 & 134,1 & 73,33 & 48,54 & 67,67 & 64,67 & 18 & 4395,83 & 3257,09 & 26,06 \\
& CMS28-10.2 & 102,0 & 57,92 & 40,77 & 69,33 & 68,67 & 16,33 & 1810,83 & 1647,88 & 21,38 \\
& Média Geral & $118,9 \mathrm{~A}$ & $64,9 \mathrm{~A}$ & $44,2 \mathrm{~A}$ & $68,8 \mathrm{~A}$ & $67,7 \mathrm{~A}$ & $18,2 \mathrm{~A}$ & $2892,2 \mathrm{~A}$ & $2259,7 \mathrm{~A}$ & $23,2 \mathrm{~A}$ \\
& $\mathrm{~N} \mathrm{~N}^{+}$ & 7,6 & 11,2 & 7,0 & 3,4 & 4,1 & 22,8 & 19,5 & 20,0 & 16,0 \\
& CV(\%) & 0,82 & 0,72 & 0,72 & 0,74 & 0,62 & 0,53 & 0,81 & 0,83 & 0,60 \\
\hline
\end{tabular}

Médias seguidas pelas mesmas letras maiúsculas na vertical não diferem estatisticamente pelo teste de agrupamento de médias Scott Knott a $5 \%$ de probabilidade 
A avaliação do teor de clorofila (Spad) mostrou, na média, que as linhagens apresentaram plantas mais amarelecidas em baixo N (TAB. 2). Miranda et al (2005), avaliando, em ambientes contrastantes em nitrogênio, o teor de clorofila em genótipos de milho, por meio de leituras fornecidas pelo aparelho portátil medidor do teor de clorofila, semelhante ao utilizado no presente trabalho (SPAD-502), demonstrou que estas leituras permitem apenas a eliminação de genótipos pouco eficientes no uso de N, sendo falhos para seleção de materiais genéticos mais eficientes. Assim, devido ao fato do teor de clorofila ter apresentado correlação genética significativa e positiva com produção de grãos em baixo $\mathrm{N}(0,63)$, a avaliação desta característica poderia auxiliar na eliminação de linhagens desta população pouco produtivas em baixo $\mathrm{N}$.

Foram observadas reduções de 24\%, 34\% e $34 \%$ no número de espigas $(\mathrm{Ne})$, peso de espigas $(\mathrm{Pe})$ e produtividade de grãos $(\mathrm{Pg})$, respectivamente, na média da população, quando comparados os ambientes com alto $\mathrm{N}$ e baixo $\mathrm{N}$ (TAB. 2). Essa redução da produtividade de grãos pode ter ocorrido, dentre outros fatores, pela diminuição da taxa fotossintética demonstrada pela redução do teor de clorofila em baixo N. Sendo o nitrogênio é um elemento essencial da estrutura da molécula de clorofila e um constituinte dos aminoácidos, sua ausência pode prejudicar as unidades de montagem das proteínas, das quais muitas têm funções enzimáticas e regulatórias importantíssimas em todo o metabolismo da planta (TAIZ; ZEIGER, 2004). Redução $37 \%$ na produtividade de grãos em baixo comparado ao alto $\mathrm{N}$ foi observada por Presterl et al (2003), estimando parâmetros genéticos quantitativos visando a otimizar programas de melhoramento buscando aumento de produtividade de grãos em genótipos de milho sob baixos níveis de nitrogênio.

O peso de 100 sementes (P100) não sofreu efeito negativo da baixa disponibilidade de N (TAB. 2). Purcino et al. (2000), analisando o efeito da nutrição nitrogenada na atividade de enzimas assimiladoras de nitrogênio na região do pedicelo-placenta-chalaza em milho, também não encontraram diferença entre híbridos de milho quanto ao peso de sementes. Esses autores sugeriram que o efeito benéfico do suplemento de nitrogênio na produção de grãos ocorre em outra variável como no número e não no peso de sementes.

A classificação prévia da linhagem CMS28-7.1 como eficiente no uso de nitrogênio foi confirmada pela elevada média de produção de grãos em baixo $\mathrm{N}\left(2.766,36 \mathrm{~kg} \mathrm{ha}^{-1}\right)$, sendo também confirmada a classificação da linhagem CMS28-10.2 como ineficiente no uso de nitrogênio, uma vez que sua produção de grãos nessa situação foi de $356,50 \mathrm{~kg} \mathrm{ha}^{-1}$, sendo inferior à média produção de grãos de toda a população avaliada (1.225,26 kg ha-1) (TAB. 2).

A herdabilidade da produtividade de grãos sofreu redução de 5,9\% em baixo $\mathrm{N}$, quando comparado ao alto N. Bertin e Gallais (2000) também encontraram valores de herdabilidade menores para características morfológicas em ambientes com baixo $\mathrm{N}$ disponível no solo em relação ao ambiente sem estresse. A herdabilidade da característica florescimento feminino não sofreu alteração entre as duas doses de nitrogênio, mas o peso de 100 grãos apresentou maior coeficiente de herdabilidade em baixo do que no alto nitrogênio (TAB. 2). Apesar disso, tal característica apresenta pouco valor prático para seleção indireta, pois sua correlação genética com a produção de grãos, na condição de estresse, foi baixa $(0,39)$.

As correlações genotípicas e ambientais apresentaram concordância de sinais tanto em baixo quanto em alto N (TAB. 3 e 4). Tal concordância indica que as causas das variações genética e ambiental influenciam essas características em mecanismos fisiológicos semelhantes (FALCONER, 1981). Comportamento semelhante em relação à concordância de sinais foi observado entre a correlação fenotípica e genotípica. Caso essa concordância de sinais não fosse observada, seria sugestivo da possibilidade de ocorrência de erro de amostragem e/ou estimativa de parâmetros.

Com relação às magnitudes, observou-se a tendência das correlações genotípicas serem superiores às fenotípicas em baixo e em alto $\mathrm{N}$, indicando que a expressão fenotípica da associação entre estes caracteres não é aumentada pelas mesmas influências do ambiente.

A produtividade de grãos em baixo $\mathrm{N}$ se mostrou correlacionada com a maioria das características avaliadas. Entretanto, as maiores magnitudes das correlações genéticas foram obtidas com o número de espigas $(0,82)$ e principalmente com o peso de espigas $(0,99)$.

Segundo Banziger et al. (1997a, 1997b), programas de melhoramento de milho que objetivam à obtenção de genótipos produtivos em ambientes com deficiência de nitrogênio poderiam incluir seleção em ambientes de baixa disponibilidade deste nutriente para maximização de ganhos de seleção, utilizando-se, também, de características secundárias para aumentar a eficiência de seleção para produção de grãos devido, normalmente, às medidas tomadas nesses caracteres serem menos sujeitas a erros de mensuração e de mais fácil medição. Assim, no presente trabalho foi apresentado que o número de espigas pode ser uma característica importante a ser utilizada na seleção indireta de genótipos de milho visando a alta produção de grãos em baixa disponibilidade de nitrogênio no solo, em função da sua alta correlação genética com o peso de grãos $(0,82)$ e alta herdabilidade $(0,60)$ em tais condições. 
Tabela 3 - Coeficientes de Correlação Genotípica $\left(\mathrm{r}_{\mathrm{ge}}\right)$, Fenotípica $\left(\mathrm{r}_{\mathrm{fe}}\right)$ e Ambiental $\left(\mathrm{r}_{\mathrm{a}}\right)$ entre produção de grãos nos ambientes com baixa e alta aplicação de N (Pg - alto N e Pg - Baixo N) e as características Teor de clorofila (Spad), Florescimento Masculino (Fm), Florescimento Feminino (Ff), em uma população de RIL avaliadas nos ensaios com Alto e Baixo nitrogênio

\begin{tabular}{cccccccccc}
\hline \multirow{2}{*}{ Nitrogênio } & \multicolumn{3}{c}{$\mathrm{Spad}$} & \multicolumn{3}{c}{$\mathrm{Fm}$} & \multicolumn{3}{c}{$\mathrm{Ff}$} \\
\cline { 2 - 9 } & $\mathrm{rf}_{\mathrm{e}}$ & $\mathrm{rg}_{\mathrm{e}}$ & $\mathrm{r}_{\mathrm{a}}$ & $\mathrm{rf}_{\mathrm{e}}$ & $\mathrm{rg}_{\mathrm{e}}$ & $\mathrm{r}_{\mathrm{a}}$ & $\mathrm{rf}_{\mathrm{e}}$ & $\mathrm{rg}_{\mathrm{e}}$ & $\mathrm{r}_{\mathrm{a}}$ \\
\hline $\mathrm{Pg}$ - Alto N & $0,36^{* *}$ & $0,39^{*}$ & $0,27^{* *}$ & $-0,19^{* *}$ & & $-0,29^{* *}$ & $-0,21^{* *}$ & $-0,22^{*}$ & $-0,21^{*}$ \\
$\mathrm{Pg}$ - Baixo N & $0,52^{* *}$ & $0,63^{* *}$ & $0,30^{* *}$ & $-0,33^{* *}$ & & $-0,34^{* *}$ & $-0,33^{* *}$ & $-0,29^{* *}$ \\
\hline
\end{tabular}

${ }^{*, * *}$ significativo a 5 e $1 \%$ pelo teste $\mathrm{t}$

Tabela 4 - Coeficientes de Correlação Genotípica $\left(\mathrm{r}_{\mathrm{ge}}\right)$, Fenotípica $\left(\mathrm{r}_{\mathrm{fe}}\right)$ e Ambiental $\left(\mathrm{r}_{\mathrm{a}}\right)$ entre produção de grãos nos ambientes com baixa e alta aplicação de N (Pg - alto N e Pg - Baixo N) e as características Número de Espigas (Ne), Peso de Espigas (Pe) e Peso de 100 sementes (P100) em uma população de RIL avaliadas nos ensaios com Alto e Baixo nitrogênio

\begin{tabular}{cccccccccc}
\hline \multirow{2}{*}{ Nitrogênio } & \multicolumn{3}{c}{$\mathrm{Ne}$} & \multicolumn{3}{c}{$\mathrm{Pe}$} & \multicolumn{3}{c}{$\mathrm{P} 100$} \\
\cline { 2 - 9 } & $\mathrm{rf}_{\mathrm{e}}$ & $\mathrm{rg}_{\mathrm{e}}$ & $\mathrm{r}_{\mathrm{a}}$ & $\mathrm{rf}_{\mathrm{e}}$ & $\mathrm{rg}_{\mathrm{e}}$ & $\mathrm{r}_{\mathrm{a}}$ & $\mathrm{rf}_{\mathrm{e}}$ & $\mathrm{rg}_{\mathrm{e}}$ & $\mathrm{r}_{\mathrm{a}}$ \\
\hline $\mathrm{Pg}$ - Alto N & $0,63^{* *}$ & $0,73^{* *}$ & $0,53^{* *}$ & $0,94^{* *}$ & $0,98^{* *}$ & $0,73^{* *}$ & $0,23 * *$ & & \\
$\mathrm{Pg}$ - Baixo N & $0,74^{* *}$ & $0,82^{* *}$ & $0,63^{* *}$ & $0,96^{* *}$ & $0,99^{* *}$ & $0,88^{* *}$ & $0,30^{* *}$ & $0,39^{*}$ & \\
\hline
\end{tabular}

${ }^{*, * *}$ significativo a 5 e $1 \%$ pelo teste $\mathrm{t}$

\section{Conclusões}

1.A população de linhagens endogâmicas recombinantes estudada apresentou variabilidade genética para produtividade de grãos em baixa disponibilidade de nitrogênio;

2. As estimativas dos coeficientes de herdabilidade e de correlação genética entre produtividade de grãos e outras características variaram de acordo com a disponibilidade de nitrogênio;

3. A aplicação do estresse proporcionou a obtenção de coeficientes de correlações genéticas, entre produtividade de grãos e outras características, de maiores magnitudes do que aquelas obtidas na avaliação sem estresse;

4. A característica número de espigas apresentou alta correlação genética com produtividade de grãos sob estresse e também maior valor de herdabilidade em relação ao ambiente com alto nitrogênio no solo, portanto, mostra-se interessante para ser usada na seleção indireta, sob estresse de N.

\section{Referências}

BÄNZIGER, M.; BETRAN, F. J.; LAFFITE, H. R. Efficiency of high-nitrogen selection environments for improving maize for low-nitrogen target environments. Crop Science, v. 37, n. 04, p. 1103-1109, 1997a.
BÄNZIGER, M.; LAFITTE, H. R. Efficiency of secondary traits for improving maize for low-nitrogen target environments. Crop Science, v. 37, n. 04, p. 1110-1117, $1997 \mathrm{~b}$.

BASTOS, E. A. et al. Doses e formas de parcelamento de nitrogênio para a produção de milho sob plantio direto. Revista Ciência Agronômica. v. 39, n. 02, p. 275-280, 2008.

BERTIN, P.; GALLAIS, A. Genetic variation for nitrogen use efficiency in a set of recombinant maize inbred line I. Agrophysiological Results. Maydica, v. 45, n. 01, p. 53-66. 2000.

CRUZ, C. D. Genes - Aplicativo computacional em genética e estatística. Viçosa: UFV, 2004.

DUARTE, J. B.; VENCOVSKY, R. Interação genótipo a ambientes: uma introdução à análise AMMI. Ribeirão Preto: Sociedade Brasileira de Genética, 1999. 60 p. (Série Monografias, 9).

EDMEADES, G. O. et al. Improving crop yields under water deficits in the tropics. In: Chopa V.L., Singh R.B. and Varna A. (eds) Crop productivity and sustainability - Shaping the Future. Proc. Second International Crop Science Congress. Oxford and IBH, New Delhi: 1998. p. 437- 451.

FALCONER, D. S. Introduction to quantitative genetics 2 . ed. London: Longman, 1981. 340 p.

FIDELIS, R. R. et al. Fontes de germoplasma de milho para estresse de baixo nitrogênio. Pesquisa Agropecuária Tropical, v. 37, n. 03, p.147-153, 2007.

GAMA, E. E. G. et al. Combining ability for nitrogen use in a selected set of inbred lines from a tropical maize population. Revista Brasileira de Milho e Sorgo, v. 01, n. 03, p. 68-77, 2002. 
GOMES, F. P. Curso de estatística experimental. 12. ed. São Paulo: Editora Piracicaba. Nobel, 1990. 468 p.

LAFITTE, R.; BLUM, A.; ATLIN, G. Using secondary traits to help identify drought-toleerant genotypes. In: FISCHER, K. S. et al.; (Ed.) Breeding rice for drought-prone environments., Los Banos Philippine: IRRI, , 2003. p. 37-48.

MIRANDA, G. V. et al. Selection of discrepant maize genotypes for nitrogen use efficiency by a chlorophyll meter. Crop Breeding and Applied Biotechnology, v. 05, p. 451-459, 2005.

PRESTERL, T. et al. Improving nitrogen-use efficiency in European maize: Estimation of quantitative genetic parameters. Crop Science, v. 43, n. 04, p. 1259-1265, 2003.

PURCINO, A. A. C. et al. Glutamina synthetase response to nitrate in maize genotypes of contrasting nitrogen use efficiency. Maydica, v. 53, n. 02, p. 101-109, 2008.

PURCINO, A. A. C. et al. Grain Filling In Maize: The Effect Of Nitrogen Nutrition On The Activities Of Nitrogen Assimilating Enzymes In The Pedicel-Placento-Chalaza Region. Maydica, v. 45, p. 95-103, 2000.

RAMALHO, M. A. P.; SANTOS, J. B.; ZIMMERMANN, M. J. de $\mathrm{O}$. Genética quantitativa em plantas autógamas: aplicação ao melhoramento do feijoeiro. Goiânia: UFG, 1993. 271 p.
SANTOS, M. X. et al. Melhoramento intrapopulacional no sintético elite NT para solos pobres em nitrogênio. I. Parâmetros genéticos de produção. Pesquisa Agropecuária Brasileira, v. 33, n. 01, p. 55-61, 1998.

SILVA, R. G. et al. Adaptabilidade de famílias de meio-irmãos de milho submetidas ao déficit hídrico e baixa disponibilidade de nitrogênio. Revista Ceres, v. 55, n.04, p. 344-351, 2008.

SOARES, M. O. et al. Discriminação de linhagens de milho quanto à utilização de nitrogênio, por meio da avaliação de caracteristicas do sistema radicular. Revista Brasileira de Milho e Sorgo, v. 08, n. 01, p. 93-103, 2009.

SOUZA, A. R. R. et al. Agronomic performance of white maize landrace in different environmental conditions. Revista Ceres, v. 55, p. 497-503, 2008.

SOUZA, L. V. et al. Combining ability of maize grain yield under different levels of environmental stress Pesquisa Agropecuária Brasileira, v. 44, n. 10, p. 1297-1303, 2009.

SZELÉS, A. The Indication of Nitrogen deficiency In Maize Growing Using Spad-502 Chlorophyll Meter. Cereal Research Communications, v. 35, n. 02, p. 1149-1152, 2007.

TAIZ, L.; ZEIGER, E. Fisiologia Vegetal, 3. ed, Porto Alegre: Artmed, 2004. 719 p. 